\title{
México y Tailandia, posibilidades a través del Pacífico
}

DOI: $10.32870 /$ mycp.v1i2.391

Jorge Luis Hidalgo Castellanos ${ }^{1}, 2$

\section{Resumen}

$\mathrm{E}$ 1 océano Pacífico es un espacio que, a lo largo del tiempo, ha servido para comunicar a América con Asia, como lo hizo la Nao de China para comerciar con las colonias españolas y vincularlas entre sí. Sin embargo, los países de uno y otro lado todavía se conocen poco.

En el ámbito latinoamericano el desconocimiento es mayor y el sureste asiático está lejos, no solo geográficamente, sino en otros campos como el cultural, el deportivo y el comercial. Este trabajo se centra en la revisión breve de algunos aspectos de las dos regiones y, sobre todo, en los vínculos entre México y Tailandia a lo largo de una relación de casi cuarenta años, con el objetivo de demostrar el potencial existente entre ambas regiones y países y la veta a explotar que ofrece, sobre todo, para el empresariado mexicano. Se destaca la limitada atención que se ha dado tanto en México como en Tailandia a la relación bilateral, pese a lo cual la cooperación y el comercio entre ambos han ido creciendo de manera constante desde 1990. Ello ofrece enormes posibilidades de aprovechar la Cuenca del Pacífico, pero requiere de un esfuerzo conjunto entre los sectores público y privado con el apoyo de la academia.

Palabras clave: México, Tailandia, relaciones, bilateral, diplomacia, cooperación, Pacífico, transpacífico, comercio

1. Artículo recibido el 28 de agosto de 2012 y dictaminado el 29 de octubre de 2012. Jorge Luis Hidalgo Castellanos: Jefe de Cancillería en la Embajada de México en Tailandia.

2. El autor agradece el apoyo del Embajador Jorge Chen y de Kittipong Nasaiya, Bernardo Miranda y Gonzalo Teherán. 


\section{Abstract}

Throughout time the Pacific Ocean has served to communicate the American continent with Asia, just as the Nao de China did for centuries as it traded with the Spanish colonies and linked them. However, the countries on either side still know little about each other.

Concerning Latin America, the ignorance is considerably greater. South East Asia is not only far geographically speaking, but also in other scopes such as culture, sports and commerce. With the aim of demonstrating the potential that exists between both regions and countries, and the advantages of further exploration, especially for the Mexican business community, this work focuses on a brief review of some aspects of the two regions, mainly on the ties between Mexico and Thailand throughout a relation of almost 40 years. Notwithstanding the limited attention given by both, Mexico and Thailand, cooperation and commerce between these two nations has been constantly increasing since 1990. This offers great possibilities for broad exploitation of the Pacific Rim, but it requires further joint efforts between the public and private sectors, with the assistance of the academia.

Key words: Mexico, Thailand, relations, bilateral, diplomacy, cooperation, Pacific, transpacific, commerce.

\section{Introducción}

Compartido por varios países, el océano Pacífico, a la vez que separa y se interpone en grandes distancias, también une y vincula cultural y comercialmente a tres continentes y miles de millones de habitantes. ${ }^{3}$ En esa vastedad marítima, confluyen América, Asia y Oceanía con la posibilidad de interactuar cada día más y mejor.

Del trío continental mencionado, dos son los que interesan a este trabajo: América y Asia. Este último en general, con $\mathrm{China}^{4}$ y Japón a la cabeza, constituye una de las regiones con mayor y más rápido crecimiento económico en el mundo y dentro de él. La amplia zona que abarcan los territorios de los

3. La Cuenca del Pacífico tiene un área de 70 millones de $\mathrm{km}^{2}$, en la que se localizan 47 países, que en conjunto tienen más de la mitad de la población mundial.

4. Sobre China y la relación con América Latina y el Caribe se recomienda leer a Hearn y LeónManríquez (2011). 
miembros de la Asociación de $\mathrm{Na}$ ciones del Sureste Asiático (ANSEA), que incluye a Tailandia, es uno de sus motores más vigorosos, con una expansión incomparable a pesar de las crisis internacionales y los desastres naturales. Es todavía uno de los lugares que brilla, si se compara con los nubarrones en Europa.

Por su parte, América, pese a los problemas enfrentados por Estados Unidos, hoy en día es otro de los motores económicos del orbe. América Latina, en particular, destaca como la segunda región del mundo en avances económicos y, de acuerdo con el Banco Mundial, el crecimiento de su PIB se ha mantenido con un $5 \%$ de promedio desde 2006. Adicionalmente, el impacto de la crisis europea en Latinoamérica ha sido menor de lo que se esperaba. México, junto con Brasil, se destaca en esta región.

Con Oceanía, en el sur del Pacífico, los vínculos latinoamericanos no han sido tan extensos, si bien los ha habido, en particular entre Perú y Australia migración incluida-, y naturalmente entre aquella y Nueva Zelanda con Estados Unidos y Canadá, debido a su similitud cultural y lingüística, entre otros factores.

Existen mecanismos que facilitan el intercambio entre ambas regiones, como el Foro Económico de Asia-Pacífico (APEC) $)^{5}$ y el Foro de Cooperación América Latina-Asia del Este (FOCALAE) y actualmente se negocia la Asociación Transpacífica (TPP, su sigla en inglés), pero más allá de ellos, depende de la voluntad real de sus miembros y de los países de ambas regiones en general, el estrechar sus relaciones y obtener ventajas mutuas para fomentar

5. Si bien es un mecanismo multilateral de cooperación, APEC se autodefine oficialmente como un foro. Ver Mission Statement, disponible en: www.apec.org/About-Us/About-APEC/MissionStatement.aspx 
su desarrollo, independientemente de la distancia y las diferencias culturales. Dentro de ambas regiones, México y Tailandia son países que muestran niveles macroeconómicos saludables y proporcionalmente similares. Al compartir más de 170 millones de habitantes en conjunto, pueden ser un ejemplo de colaboración bilateral, particularmente en el terreno comercial, para lo cual no es necesario un marco de acuerdos regionales económicos, aunque es innegable que su existencia y la pertenencia a ellos representan oportunidades. Otros aspectos de colaboración real latente están en lo político -incluyendo el multilateralismo-, lo cultural y la cooperación.

Un breve repaso a la relación bilateral, resaltando la diplomático-comercial y el potencial económico tailandés, así como la atención que recíprocamente se han dado estas naciones, inclusive en lo académico, permite vislumbrar las posibilidades que México tiene en Tailandia y la necesidad evidente de que ambos se conozcan más.

\section{El sureste asiático}

Con casi 600 millones de habitantes, la mayoría de clase media ${ }^{6}$, distribuidos en 10 países, la zona de la ANSEA significa un importante mercado interno para los productos de otras regiones del mundo, incluyendo la latinoamericana. Esta región de Asia pasó, de tener un comercio total de 302 mil millones de dólares (mmd) en 1990, a 2 millones de millones (mmdd) en 2010. En contrapartida, 578 millones de seres humanos en Latinoamérica representan un número de consumidores considerable para los empresarios asiáticos, lo que puede estimular su ya creciente economía.

Algunos datos indican que en el sureste asiático existe interés por Latinoamérica y el Caribe, por lo menos en cuanto al comercio se refiere, pero que también se refleja en la cultura y el deporte, destacando el cine y la música en la primera y el fútbol en el segundo, gracias a las figuras mexicanas en las ligas europeas y la exitosa participación mexicana en recientes eventos deportivos internacionales, como las Olimpiadas de Londres 2012. La realización desde 2010 de foros y seminarios sobre negocios y comercio entre ambas regiones,

6. 500 millones de personas dentro de la clase media, de acuerdo con notas periodísticas de académicos de la Escuela de Políticas Públicas de la Universidad Nacional de Singapur. Ver: Mahbubani (2012), 18 June. 
incluida Tailandia, ${ }^{7}$ con la presencia de ministros y otros altos funcionarios de los países involucrados, amén de conferencias y otros actos académicos sobre América Latina y el Caribe, APEC, ANSEA y TPP, son muestra de ello. Solamente en los primeros siete meses de 2012 se organizaron dos eventos oficiales $^{8}$ en países de la ANSEA.

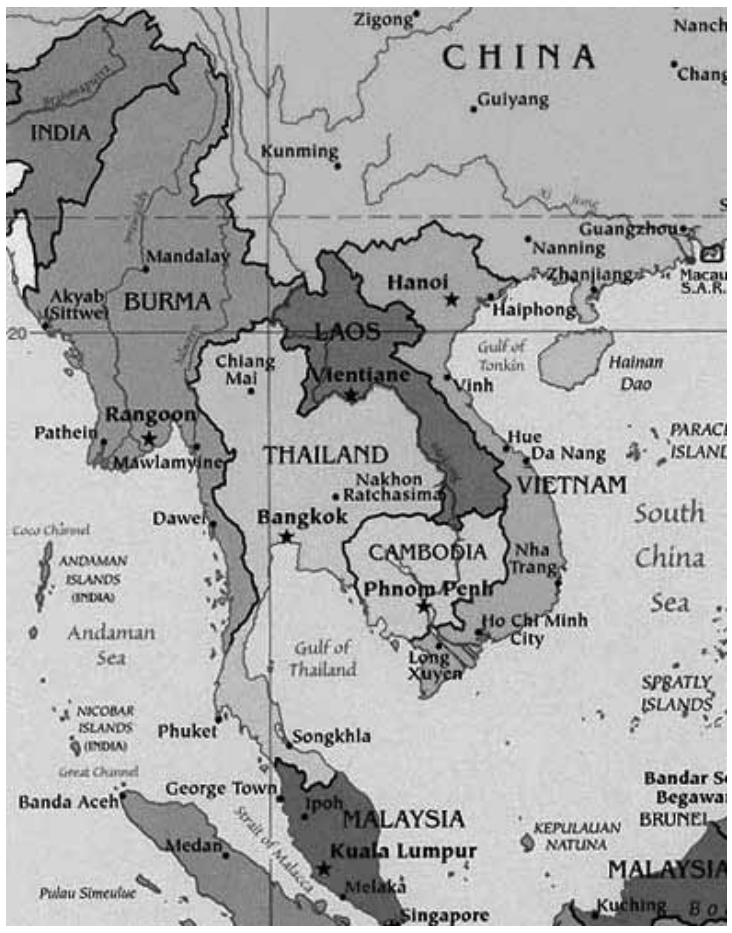

Las visitas empresariales ${ }^{9}$ y de Jefes de Estado o de Gobierno y altos funcionarios a uno y otro continente en los recientes años también contribuyen a afirmar el interés asiático en Latinoamérica. Por ejemplo, el presidente de

7. Latin Business Forum 2010, 18 de noviembre de 2010. Organizado por la oficina del Representante de Comercio de Tailandia (TTR, su sigla en inglés) en el Palacio de Gobierno, Bangkok.

8. The Vietnam-Latin America Ministerial Forum on Trade and Investment, 5 y 6 de julio, Hanoi, y The ASEAN-Latin America Business Forum 2012, 9 y 10 de julio en Yakarta, Indonesia. En este último participó el Secretario de Economía de México. En la capital mexicana se llevó a cabo, a fines de septiembre de 2012, el taller "La relación bilateral México-Tailandia” en el Colegio de México.

9. En abril de 2011 una misión empresarial organizada por la TTR realizó un viaje a algunos países latinoamericanos, incluyendo México. Por su parte, la oficina comercial tailandesa en México promovió un viaje de hombres de negocios a Tailandia. 
Indonesia ${ }^{10}$ en junio y el canciller tailandés en agosto de 2012 estuvieron en Sudamérica ${ }^{11}$. No obstante, más se requiere por parte de México para atraer inversiones y promover las exportaciones, entre otras cosas, con una mayor y mejor presencia de ProMéxico ${ }^{12}$ en la subregión y el apoyo de las misiones diplomáticas, lo que incluye capacitación e incremento de los recursos humanos.

\section{Latinoamérica y Asia-Pacífico}

La perogrullada de que América y Asia son dos continentes apartados y diferentes, pero unidos por un océano, representa una gran oportunidad con más ventajas que desafíos. La historia lo demuestra así, por lo menos desde el siglo XVI. El Pacífico ha sido, a la vez que un amplio vacío que separa, un medio que ha servido para vincular en diversos ámbitos a dos regiones geográficas distantes. A lo largo de los siglos, por lo menos desde que los europeos llegaron a América, la comunicación con Asia ha sido continua y comenzó a través de lo que hoy es México, entonces un virreinato del imperio español y su influencia, aunque pequeña, si se le compara con la del viejo continente, existió y fue mutua.

La ruta entre la entonces Nueva España y las Filipinas fue la primera vía transpacífica oficial establecida por la potencia ibérica para comerciar y controlar sus territorios de ultramar. El idioma y la religión también sirvieron para vigilar ambas zonas del mundo, vinculándolos obligatoriamente en beneficio de Europa, especialmente cuando otras rutas quedaron obstruidas. De hecho, la vía establecida por los españoles logró unir a Europa, América y Asia de una forma inalterada hasta el siglo XIX.

Las relaciones transpacíficas pues, no son nuevas y en mayor o menor medida han continuado hasta nuestros días sin que hayan sido todavía aprovechadas en su totalidad. Los diversos países de uno y otro continente, por diferentes razones, han sostenido relaciones a lo largo del tiempo, de manera

10. El presidente Susilo Bambang Yudhoyono realizó una visita de Estado a Ecuador y Colombia, 22-26 de junio de 2012, después de haber participado en la Cumbre del G-20 en Los Cabos, BCS, México y en la conferencia de NN UU Río+20 sobre Desarrollo Sustentable, en Río de Janeiro, Brasil.

11. El Ministro de Asuntos Exteriores Surapong Tovichaichaikul estuvo en Chile y Brasil del 14 al 18 de agosto de 2012.

12. Datos de ProMéxico señalan textualmente que su oficina en Singapur atiende a siete de los diez miembros de ANSEA, incluyendo Tailandia, pero Camboya, Laos y Myanmar, no se enlistan como países atendidos por oficina comercial mexicana alguna en el exterior en el portal electrónico oficial de ProMéxico. Ver www.promexico.gob.mx. 
individual o bilateral o a través de mecanismos regionales como $\operatorname{APEC}^{13} \mathrm{y}$ FOCALAE, ${ }^{14}$ sin que realmente se haya aprovechado todo el potencial existente, ni abarcado todas las áreas de cooperación a lo largo y ancho del área que comprende la Cuenca del Pacífico.

La propuesta, en años recientes, de relacionar a través del océano Pacífico a varios países de una y otra orilla solo recoge lo que la historia ya ha mostrado, enfocándola en el comercio, con la participación de naciones con amplio potencial exportador y económico en general. Así, la Asociación Transpacífica ${ }^{15}$ (TPP) se perfila como un tratado de libre comercio de gran envergadura que puede traer ventajas a más 1,500 millones de personas. No obstante, lo ambicioso del proyecto y la multiplicidad de actores tan disímiles que tendría, permite prever un largo periodo de negociaciones que los países pueden aprovechar para beneficio propio, de manera bilateral.

Lo anterior deja ver que existe un interés a nivel regional que, sin embargo, no se refleja necesariamente en el ámbito nacional, donde debe incluirse al sector privado con el apoyo gubernamental. Al final, son los exportadores quienes hacen los negocios y el gobierno el que puede facilitarlos.

México, por ejemplo, ha estado presente en Asia y Oceanía (Asia-Pacífico) desde hace décadas. Fue la primera economía latinoamericana en integrarse a APEC en 1993 y mantiene once embajadas y cuatro oficinas consular-comerciales ${ }^{16}$ en esos continentes. Sin embargo, de los acuerdos comerciales que ha

13. Mecanismo multilateral establecido en 1989 con el fin de consolidar el crecimiento y la prosperidad de las naciones o economías del Pacífico. Se centra en asuntos comerciales y de inversiones. En conjunto, las 21 economías representan más del $45 \%$ del comercio total mundial y el $56 \%$ de la producción global. Tailandia es miembro fundador del mecanismo y México ingresó en 1993 como el primer país latinoamericano de APEC. Su más reciente reunión de líderes fue en Vladivostok, en septiembre de 2012.

14. FOCALAE es un mecanismo establecido en 1998 como FALAE, que adoptó su nuevo nombre en 2001. Reúne a 34 países (16 asiáticos y 18 latinoamericanos) de ambas regiones, incluidos México y Tailandia, con el objetivo de promover el entendimiento mutuo, el diálogo político y económico y la cooperación. Su sigla en inglés es FEALAC y su más reciente cumbre fue en Tokio en 2010.

15. Si bien se estableció en 2004, la idea de ampliarla surgió en 2008 a iniciativa de Estados Unidos y otros países. Actualmente forman parte de la TPP cinco países americanos: Canadá, Chile, Estados Unidos, México y Perú. Por Asia-Pacífico están seis: Australia, Brunei Darussalam, Malasia, Nueva Zelanda, Singapur y Vietnam y existe la posibilidad de que Tailandia también se interese.

16. Las embajadas mexicanas en Asia están en: China, Corea, Filipinas, Malasia, Indonesia, Japón, Tailandia, Singapur y Vietnam. Y en Oceanía: Australia y Nueva Zelanda. Adicionalmente, existen los consulados de México en Hong Kong, Shanghai y Guangzhou en China y la Oficina de Enlace en Taipei. 
suscrito México y que dan acceso preferencial a más de cuarenta países en el mundo, solamente uno está en Asia-Pacífico, ${ }^{17}$ instrumento que, por cierto, ha alentado las exportaciones mexicanas. De los once tratados de libre comercio y de los seis acuerdos de complementación económica ( $\mathrm{ACE})^{18}$ que México ha firmado ninguno ha sido con un país de esta región y de los veintiocho acuerdos de promoción y protección reciproca de inversiones (APPRI), solamente cinco son con países de Asia-Pacífico. ${ }^{19}$

Por otra parte, recientemente México estableció, junto con Colombia, Chile y Perú, la Alianza del Pacífico ${ }^{20}$. En junio de 2012, México también fue invitado formalmente a sumarse al esquema de la $\mathrm{TPP}^{21}$ ampliada como el $10^{\circ}$ país de la iniciativa transpacífica que pretende establecer una extensa área de libre comercio a través del mayor océano del mundo, instrumento del que forma parte Chile y en cuyas negociaciones también participa Perú. Tailandia podría unirse a este grupo de negociadores de la TPP. No obstante, existen consideraciones que observan la necesidad de voltear más hacia Asia, con la posibilidad de que el nuevo gobierno mexicano lo impulse, si se considera lo que el PRI ${ }^{22}$ hizo público durante la campaña política presidencial de 2012 (Montaño y Lozoya, 2012), al referirse a Asia como un continente en el que hay que enfocar la atención y subsanar la "ausencia total de coordinación entre el gobierno y la iniciativa privada para promover a las empresas mexicanas" en la región y en particular en China. Eso también es aplicable a Tailandia. Existe, en ese sentido, la posibilidad de que México pueda enfocarse en Asia,

17. Se trata del Acuerdo de Asociación Económica México-Japón (Economy Partnership Agreement between Mexico and Japan), firmado en 2004 y en vigor desde 2005.

18. México tiene ACE con Argentina, Brasil, Cuba, Perú, Mercosur (Paraguay y Uruguay).

19. Australia, China, Corea, India y Singapur.

20. Establecida formalmente por los presidentes de los cuatro países el 6 de junio de 2012 en Atacama, Chile.

21. Actualmente son once los países que negocian la TPP, establecida originalmente por cuatro miembros (Chile, Singapur y Nueva Zelanda, además de Brunei Darussalam que se unió como parte casi de inmediato en 2005); en 2008 se incluyeron a las negociaciones de ampliación Estados Unidos, Australia, Perú y Vietnam; en 2010 Malasia; y México y Canadá en 2012. La $13^{a}$ ronda de negociaciones se llevó a cabo en San Diego, California. en julio de 2012.

22. Los autores esbozan algunos aspectos de lo que el gobierno del PRI abarcaría en su programa de política exterior en caso de llegar a la presidencia de la República y que se espera se realice, dado que los resultados de la elección de julio dieron el triunfo al candidato priista. Sobre Asia manifiestan que: "Hay una gran ausencia de México: de conocimiento y de comprensión de lo que está pasando en Asia. Esta región está cambiando la forma como vemos al mundo. No es solo la región que más está creciendo, sino la que está teniendo cambios más dramáticos en términos geopolíticos y económicos. En México, esto ni siquiera se está discutiendo". 
no solo para diversificar sus relaciones, sino para beneficiarse realmente. Hay que recordar que Asia es el destino de, al menos, 3.3\% de las exportaciones mexicanas y origen de $30.9 \%$ de sus importaciones, lo que ha resultado en un desequilibrio en la balanza comercial.

\section{El papel de Tailandia}

Tailandia, por sí sola es una potencia comercial, altamente dependiente de las exportaciones, cuyo volumen en 2011 aumentó 16\% y representan más de dos tercios de su PIB. Sin embargo, en su balanza comercial global de ese año Tailandia tuvo un déficit de $240 \mathrm{mdd}$. Su principal socio comercial desde 2010 es China, país al que se triplicaron las exportaciones tailandesas en una década. ${ }^{23}$

El otrora reino de Siam cuenta con once tratados de libre comercio, de los cuales cinco son bilaterales y seis como miembro de la ANSEA (ver cuadro 1). Es miembro de $\mathrm{APEC}^{24}$ desde 1989 (Amparo Tello, 2001: 26), ingresó a la OMC en 1995 y pertenecerá a la Comunidad Económica de ANSEA (AEC, por sus siglas en inglés) que se establecerá en enero de 2015, abarcando diez países, en un área conjunta de 4.46 millones de $\mathrm{km}^{2}$, con 600 millones de habitantes (ASEAN, 2012), potenciales consumidores. ${ }^{25}$

\section{Cuadro 1}

Tratados de Libre Comercio de Tailandia (cronología)

\begin{tabular}{ll}
\hline TLC & Fecha de entrada en vigor \\
\hline Tailandia - Australia & 1 de enero, 2005 \\
Tailandia - Nueva Zelanda & 1 de julio de 2005 \\
Tailandia - Japón & 1 de noviembre de 2007 \\
Tailandia-India & 1 de septiembre de 2004 \\
ANSEA-China & 1 de octubre de 2003 \\
ANSEA-Corea & 1 de enero de 2010 \\
ASEAN-Australia-Nueva Zelanda & 12 de marzo de 2010 \\
ANSEA-India & 1 de enero de 2010 \\
ANSEA-Japón & 1 de junio de 2010 \\
Tratado de Libre Comercio de la ANSEA (AFTA) & 1 de enero de $2002-5 \%$ \\
& 1 de enero de $2010-0 \%$ \\
Tailandia-Perú & 31 de diciembre de 2011
\end{tabular}

23. Para mayores datos, ver el análisis económico de The Report. Thailand 2012.

24. Tailandia presidió APEC en 2003 mientras que México lo hizo un año antes, en 2002.

25. Mayores datos pueden consultarse en el catálogo: ASEAN (2009). 
Si bien su relación comercial se centra en los países asiáticos, en particular sus vecinos Camboya, Laos, Myanmar y Vietnam (CLMV), Japón y China, entre otras razones, por la cercanía geográfica, también es cierto que Tailandia comercia con Estados Unidos, Europa y Oceanía y otras regiones como el Medio Oriente y Latinoamérica, la cual queda al final, con solamente $1 \%$ del total de sus importaciones, ${ }^{26}$ (gráfica 1 ) de los cuales, dos tercios habrían correspondido solo al intercambio con Brasil. En cuanto a las exportaciones tailandesas, la región se incluye en el $14 \%$ correspondiente al resto del mundo y conforme a datos oficiales mexicanos 3,088 mdd fueron hacia México, lo que permite ver el potencial exportador tailandés. El comercio con Brasil durante 2011 alcanzó los 4,532 mdd, con un volumen de exportaciones brasileñas de 2,266 mdd, lo que muestra una balanza equilibrada, con un ligero superávit para el gigante sudamericano. ${ }^{27}$, pero respecto de México es deficitario.

Por su parte, Perú comerció en 2011 con Tailandia un total de 707 mdd, con déficit de $178 \mathrm{mdd} .{ }^{28}$ Mientras que Chile mostró un comercio en el mismo año que también favoreció al reino asiático. ${ }^{29}$

Si bien continúa siendo el principal exportador mundial de arroz, lejos quedó la Tailandia basada en el sector agrícola de principios de la segunda mitad del siglo xx (Falck, 2001: 34) para convertirse en un reino exportador de manufacturas y de productos especializados, como los electrónicos. ${ }^{30} \mathrm{Si}$ no un "tigre", como se le denominó en los 90, la posición geoestratégica de Tailandia la hace ser un sitio atractivo para las empresas transnacionales que

26. Los datos oficiales de México y Tailandia difieren, lo que se presta a discrepancias. El ITC en Ginebra elabora estadísticas con base en la información proporcionada por los gobiernos. Se dice que ese $1 \%$ equivale a 2,889 mdd, de los cuales 1,800 corresponderían solo al intercambio con Brasil. Sin embargo, otras fuentes señalan que el comercio bilateral con Tailandia fue de más de 4,500 mdd, superavitario para Brasil.

27. Según datos de COMTRAde, a diferencia de México, Tailandia tiene un déficit de 0.21 mdd con Brasil, dado que exportó en 2011 2,265.96 mdd. Sin embargo, del intercambio total, Tailandia exportó a Brasil 313.5 mdd en el sector de automotores y autopartes, mientras que importó de Brasil solamente 36.6 mdd. Los datos de la SECEX brasileña, no obstante, indican un saldo negativo de poco más de 581 mdd para Brasil. Ver www.desenvolvimento.gov.br/sitio/interna/ index.php?area $=5$

28. Conforme datos de sunat, el comercio total durante 2011 fue de $707 \mathrm{mdd}$, con exportaciones peruanas por 265 mdd e importaciones tailandesas de $442 \mathrm{mdd}$. El tratado de libre comercio entró en vigor en diciembre de 2011.

29. Chile exportó a Tailandia bienes por un monto de 330,954,716 dólares e importó un total de 618,406,054 durante 2011 según datos de ProChile.

30. La autora menciona que en los años 50 y 60 la agricultura era la actividad predominante y representaba el $40 \%$ del PIB, empleando al $82 \%$ de la fuerza laboral del país. 


\section{Gráfica 1}

Importaciones tailandesas por país de origen

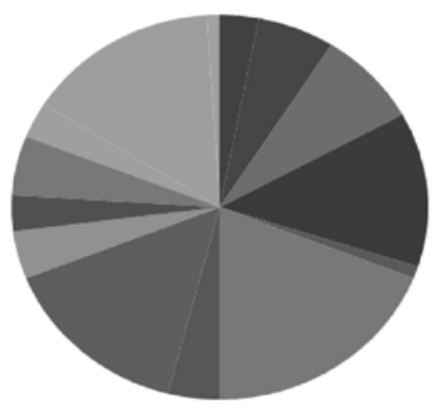

\begin{tabular}{|c|c|}
\hline Australia & \\
\hline - EUA & $6 \%$ \\
\hline UE & \\
\hline Medio Oriente & \\
\hline India & \\
\hline Japón & \\
\hline Corea del Sur & \\
\hline China & \\
\hline Resto de ASEAN & \\
\hline Singapore & \\
\hline Malasia & \\
\hline CLMV & \\
\hline Resto & \\
\hline America Latir & \\
\hline
\end{tabular}

Fuente: Elaboración propia con datos del Banco de Tailandia, Reporte mensual, 30 de Abril de 2012.

desean ingresar al mercado regional (Falck, 2001: 34), tal como lo ven los japoneses y otros extranjeros.

En ese sentido, Tailandia forma parte de las cadenas de valor productivas en la que se inserta el $50 \%$ del comercio mundial, lo que la hace interdependiente, igual que a México. El 25\% de la producción mundial de discos duros para computadoras se produce en Tailandia, de donde se exportan a China y otros países, en donde se ensamblan y terminan los productos de Apple y Lenovo, por ejemplo.

Un sector comercial sirve de ejemplo a lo antes dicho y evidencia la capacidad exportadora de Tailandia: el automotriz. En 2011 Tailandia ocupó el lugar número 14 de la lista de mayores productores de automóviles, ${ }^{31}$ por encima del Reino Unido, mientras que México obtuvo el $8^{\circ}$ lugar, inmediatamente después de Brasil. Se estima que en 2012 Tailandia pueda posicionarse como el $10^{\circ}$ productor mundial, con 2,100,000 unidades fabricadas por 16 compañías y casi 2,400 empresas proveedoras, incluso de capital mexicano. En 2011, este país aportó el 31\% de la producción total de automóviles en la zona de la

31. Datos de la Asociación de la Industria Automotriz de Tailandia (TAIA, su sigla en inglés). En 2010 estaba en el lugar número 12 y cayó como consecuencia de las inundaciones del segundo semestre de 2011 y el impacto del terremoto y tsunami en Japón, que afectaron varias plantas armadoras. 
ANSEA, solamente por debajo de Indonesia y bastante más arriba que Malasia; es decir, la mayor parte en esta región de Asia. La ventaja comparativa de Tailandia reside en los vehículos tipo pick-up, autos ecológicos y autopartes, además de tener centros de desarrollo e investigación automotriz. Empresas como BMW, Ducati, Ford, General Motors, Honda, Hino, Isuzu, Mazda, Mitsubishi, Kawasaki, Toyota y Volvo tienen plantas productoras en Tailandia.

\section{México y Tailandia}

Las relaciones diplomáticas de México con Tailandia se establecieron en 1975 y desde entonces no se han presentado problemas o disputas. Sin embargo, también es cierto que a lo largo de 37 años de relaciones bilaterales, ${ }^{32}$ poco se ha escrito o estudiado en México sobre Tailandia y sobre la relación bilateral, y menos aún en el reino tailandés. Las escasas noticias que aparecen en los medios informativos de ambos países no dejan una buena imagen en el público, sobre todo en el de Tailandia. En la república mexicana, los intentos académicos para difundir el conocimiento de Asia en general, y de Tailandia en particular, son pocos y se centran en la ciudad de México, Guadalajara y Colima, donde existen centros universitarios con departamentos dirigidos a estudiar el tema. Uno de ellos es el que edita esta revista, que sin embargo, en más de 20 años ha publicado menos de 20 artículos sobre Tailandia, al igual que de Filipinas y poco sobre Indonesia o Malasia, sin mencionar a Timor Leste, Camboya, Vietnam, Laos, Myanmar y otros miembros de la ANSEA (Falck, 2010: 9) como Brunei, si bien hay que considerar que México y la Cuenca del Pacífico editó un número exclusivo sobre Tailandia en 2001.33

En Tailandia, el escenario es yermo, los especialistas no han escrito sobre México, lo que sin embargo no ha sido óbice para que los negocios y el comercio hayan aumentado paulatina pero constantemente desde 1990. La proporción del comercio entre Asia y México se reproduce en la de este país con Tailandia, es decir, que es de diez a uno. Ello lleva a una conclusión simple: México debe exportar más a Tailandia para equilibrar la balanza comercial y para ello se requiere que los empresarios mexicanos vendan más a los tailandeses. Aquí es

32. Las relaciones diplomáticas se establecieron el 28 de agosto de 1975. Tailandia abrió su embajada en la ciudad de México en 1978 y México en Bangkok en septiembre de 1989, si bien desde 1983 tiene un Consulado Honorario en la capital tailandesa.

33. Ver la edición de 2001: "Tailandia", México y la Cuenca del Pacífico, 4(12), 99, Universidad de Guadalajara, Guadalajara. 
donde cobra relevancia el hecho de que los centros de estudio dediquen más a la investigación de este mercado y el exportador mexicano sea capaz de fomentar esos estudios para conocerlo y no tener temor de conquistarlo. Algunos datos de México y Tailandia, como los del cuadro 2, correspondientes a los años 2010 y 2011, resultan útiles para conocerlos un poco y poder compararlos.

En cuanto al marco jurídico bilateral, no obstante algunas aseveraciones (Ramírez, 2009: 103), es muy limitado si se consideran casi cuatro décadas de relaciones diplomáticas. Estrictamente hablando, existen solo tres acuerdos bilaterales, ${ }^{34}$ uno de ellos para suprimir el visado a diplomáticos. Otros tantos interinstitucionales de índole empresarial y académica que han tenido una instrumentación restringida. La relación en materia de tratados se ha reactivado por parte de México con el ánimo de reforzar la relación bilateral. Prueba de ello es el Memorándum de Entendimiento sobre consultas políticas $^{35}$ firmado a fines de 2011 y las propuestas ${ }^{36}$ de acuerdos bilaterales en materia de asistencia jurídica penal, aduanera, narcotráfico, turismo ${ }^{37}$ y doble tributación, con el fin de colaborar conjuntamente en el combate a la delincuencia transnacional, estimular el comercio y las inversiones y promover el turismo de la región hacia México. Adicionalmente, con el ánimo de activar y poner en marcha el contenido del convenio cultural y educativo firmado en 2003 por los gobiernos de México y Tailandia, se negoció entre 2011 y 2012 un convenio de cooperación académica entre universidades con el objetivo de estimular el conocimiento mutuo y realizar investigaciones, a través de sus centros especializados en el Pacífico ${ }^{38}$ encaminadas a fomentar el comercio y las relaciones culturales entre ambos países.

34. Ver México: Relación de Tratados en vigor 1836-2010.

35. Firmado en Honolulu el 11 de noviembre de 2011 por los cancilleres de ambos países, en el marco de la XIX Reunión de líderes de APEC y XXIII Reunión Ministerial de dicho mecanismo regional. El instrumento permite usar un esquema flexible para llevar a cabo encuentros bilaterales aprovechando otras reuniones internacionales o de foros, organismos o mecanismos regionales o multilaterales y tener un diálogo fluido en varios temas de interés común.

36. Desde 2003, México propuso algunos proyectos de acuerdo, a los que se han unido otros en 2007, 2010 y 2011. En todos los casos, las autoridades tailandesas han demorado su respuesta, algunas de las propuestas presentan incompatibilidades constitucionales en Tailandia que han frenado el proceso de negociación.

37. En materia turística México pretende incluir acuerdos no solo con Tailandia sino también con Malasia, Indonesia y Singapur ampliando el marco jurídico bilateral.

38. En julio de 2011 se propuso un acuerdo para vincular a la Universidad de Guadalajara, a través de su Departamento de Estudios del Pacífico y la Universidad Thammasat en Bangkok, que tiene un Centro de Estudios sobre APEC. Se espera suscribir el acuerdo en noviembre de 2012, 
Así pues, la aseveración de que "México y Tailandia tienen aún mucho que explorar" (Ramírez, 2009: 103) continua vigente porque poco se ha hecho de manera institucional y como parte de una política que permita un mayor conocimiento mutuo y aprovechar las oportunidades que cada país brinda. Pero el asunto no debe quedar en la labor de uno de los involucrados, ambos países deben promover que se les conozca más y mejor, puesto que el beneficio es mutuo.

\section{Cuadro 2}

Indicadores económicos México-Tailandia

\begin{tabular}{|c|c|c|c|c|}
\hline & México & & Tailandia & \\
\hline Indicadores & 2010 & 2011 & 2010 & 2011 \\
\hline Población (millones) & 112.3 & 113.7 & 63.9 & 64.1 \\
\hline $\begin{array}{l}\text { Tasa de Crecimiento de población } \\
\text { real }(\Delta \%)\end{array}$ & 4.4 & 1.2 & 0.6 & 0.3 \\
\hline PIB (mmdd) & $1,035.9$ & $1,185.2$ & 318.5 & 345.6 \\
\hline PIB posición mundial & 14 & 14 & 29 & 32 \\
\hline Crecimiento del PIB real $(\Delta \%)$ & 5.4 & 3.9 & 7.8 & 0.1 \\
\hline PIB per cápita (dólares) & 9,218 & 10,153 & 4,992 & 5,394 \\
\hline Inflación (\%) & 4.4 & 3.8 & 3 & 3.5 \\
\hline $\begin{array}{l}\text { Desempleo (\% PEA, promedio } \\
\text { anual) }\end{array}$ & 5.4 & 5.2 & 1 & 1.2 \\
\hline Exportaciones (mmdd) & 298.3 & 349.6 & 195.3 & 228.3 \\
\hline Importaciones (mmdd) & 301.5 & 350.9 & 182.4 & 230.4 \\
\hline Principales socios comerciales & $\begin{array}{l}\text { Estados } \\
\text { Unidos }\end{array}$ & $\begin{array}{c}\text { Estados } \\
\text { Unidos China }\end{array}$ & $\begin{array}{l}\text { Japón } \\
\text { China }\end{array}$ & $\begin{array}{c}\text { Japón China } \\
\text { Estados }\end{array}$ \\
\hline Primero Segundo Tercero & $\begin{array}{l}\text { China } \\
\text { Canadá }\end{array}$ & Canadá & $\begin{array}{l}\text { Estados } \\
\text { Unidos }\end{array}$ & Unidos \\
\hline $\begin{array}{l}\text { Grado de apertura (Com. Tot. } \\
\text { Sobre \% del PIB) }\end{array}$ & 57.9 & 59.1 & 118.6 & 132.7 \\
\hline $\begin{array}{l}\text { Índice de Desarrollo Humano } \\
\text { (ONU) }\end{array}$ & $58^{\circ}$ & $57^{\circ}$ & $103^{\circ}$ & $103^{\circ}$ \\
\hline
\end{tabular}

con lo que sería el primer instrumento interinstitucional registrado por el gobierno federal que se firma en el marco del Convenio de Cooperación Cultural y Educativa entre México y Tailandia de 2003. 
México y Tailandia, posibilidades a través del Pacífico

\begin{tabular}{|c|c|c|c|c|}
\hline & México & & Tailandia & \\
\hline Indicadores & 2010 & 2011 & 2010 & 2011 \\
\hline $\begin{array}{l}\text { Índice de Competitividad "Doing } \\
\text { Business 2012" del Banco } \\
\text { Mundial }\end{array}$ & - & $54^{\circ}$ & - & $16^{\circ}$ \\
\hline $\begin{array}{l}\text { Índice de Competitividad "Travel } \\
\text { \& Tourism" del Foro Económico } \\
\text { Mundial }\end{array}$ & - & $43^{\circ}$ & - & $41^{\circ}$ \\
\hline $\begin{array}{l}\text { Índice "Global Gender Gap } \\
\text { Report" del Foro económico } \\
\text { mundial }\end{array}$ & $91^{\circ}$ & $89^{\circ}$ & $57^{\circ}$ & $60^{\circ}$ \\
\hline $\begin{array}{l}\text { Tipo de cambio (unidad } \\
\text { monetaria/ dólar fin de periodo) }\end{array}$ & 12.64 & 12.43 & 31.73 & 30.99 \\
\hline $\begin{array}{l}\text { Inversión Extranjera Directa-ied } \\
\text { (mdd) }\end{array}$ & $17,725.9$ & $19,439.8$ & $9,689.8$ & $9,539.0$ \\
\hline $\begin{array}{l}\text { Deuda Bruta Total del Gob. Fed. } \\
\text { (\% PIB) }\end{array}$ & 42.9 & $43.8^{*}$ & 42.6 & 41.1 \\
\hline $\begin{array}{l}\text { Reservas internacionales } \\
\text { (mmdd) }\end{array}$ & 120.6 & $153.9^{*}$ & 172.0 & 179.2 \\
\hline Remesas (mdd) & 22.6 & 22.7 & 1.8 & - \\
\hline Comercio bilateral (mdd) & $2,846.5$ & $3,408.5$ & $1,365.5$ & $1,880.0$ \\
\hline Exportaciones Importaciones & 148.6 & 319.7 & 967 & 1271.1 \\
\hline Saldo & $\frac{2697.9}{-2549.3}$ & $\frac{3088.8}{-2769.1}$ & $\begin{array}{r}398.5 \\
+568.5\end{array}$ & $\begin{array}{r}608.9 \\
+662.2\end{array}$ \\
\hline $\begin{array}{l}\text { Inversión en México 1999-dec. } \\
2011 \text { (mdd) }\end{array}$ & & 0.1 & & \\
\hline Inversión mexicana (mdd) & & 28.04 & & \\
\hline
\end{tabular}

Fuentes: Elaboración propia con datos de: BANXICO, SHCP, Secretaria de Economía, INEGI, Bancos Centrales, Ministerios de Finanzas y/o Instituciones de Estadísticas, Foro Económico Mundial, Fondo Monetario Internacional, Organización Mundial del Comercio, Banco Mundial. mmdd= Miles de millones de dólares; mdd= Millones de dólares; $\Delta \%$ = Porcentaje aumentado; *valor en dólares con tipo de cambio 13.21.

\section{El comercio bilateral}

El comercio total bilateral ${ }^{39}$ en 2010 , de acuerdo con las instituciones mexicanas, fue de 2,847 millones de USD (mdd) y de 3,409 mdd en 2011, lo que ubica

39. Cifras de la Secretaría de Relaciones Exteriores (SRE) con datos de la Secretaría de Economía y del Banco de México. Principales socios comerciales de México en 2011. 
a Tailandia como el $19^{\circ}$ socio comercial de México y el $7^{\circ}$ en Asia y Oceanía. Entre los principales socios de México en el sureste asiático destacan Malasia, en el lugar 12 mundial y $5^{\circ}$ en la región, Singapur en el 27 y Filipinas en el 28. Obviamente el comercio en esa región está dominado por China, con el lugar 2 y Japón en el 4, además de Australia, en el lugar 25.

\section{Gráfica 2}

Comercio Bilateral

(1990 a 2011)

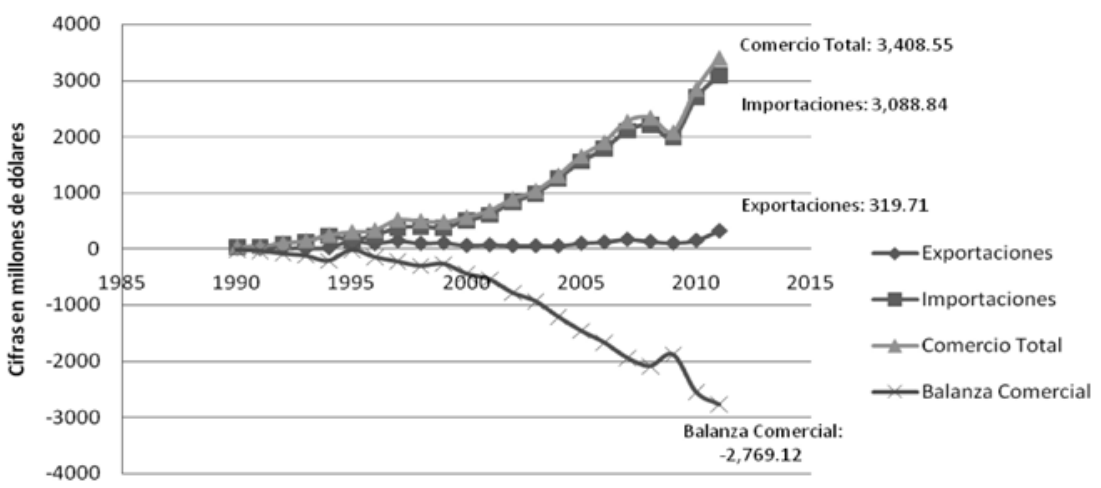

Fuente: Elaboración propia con datos de la Secretaría de Economía de México

Si bien la balanza comercial mundial de México está equilibrada, con un ligero déficit, esta es negativa respecto de Tailandia, de la que se importa casi diez veces más de lo que se le vende (3,089 mdd contra 320 mdd). Durante el primer semestre de 2012, las cifras casi alcanzaron los 1,900 mdd, lo que permite estimar que al finalizar el año podrían alcanzar los 4,000 mdd (gráfica 3), pero no tendrán una modificación significativa en su equilibrio.

Tailandia, no obstante, no se encuentra entre los principales países inversionistas en México y no lo será en el corto plazo, ${ }^{40}$ entre otras razones, debido a que se enfocará en sus vecinos y el AEC, sobre todo, ante la apertura de países como Myanmar, Laos y Camboya. Dentro de la ANSEA, por cierto, solo dos -Filipinas y Singapur-aparecen en la lista de los 10 mayores inversionistas de Asia y Oceanía en la república mexicana, con Japón a la cabeza con

40. Según datos de la Secretaría de Economía mexicana, en 2010 la inversión de Asia y del sureste asiático en el mundo fue de 103 mmd, de lo que a México llegó menos de 1\%. 
2,983.6 mdd y China en el $6^{\circ}$ lugar, con 156.9 mdd. Jalisco, por cierto, es uno de las entidades federativas que más ha recibido inversión extranjera directa (IED) de la región con 804.7 mdd, solamente detrás del Distrito Federal, lo que coloca al estado en el $6^{\circ}$ lugar a nivel nacional.

\section{Cuadro 3}

Comercio entre México y Tailandia, (1990-2011)

(Valores en millones de dólares)

\begin{tabular}{lrrrr}
\hline Año & Exportaciones & Importaciones & Comercio Total & Balanza Comercial \\
\hline 1990 & 11.200 & 33.628 & 44.828 & -22.428 \\
1991 & 4.461 & 43.157 & 47.618 & -38.696 \\
1992 & 8.703 & 101.535 & 110.238 & -92.832 \\
1993 & 10.892 & 138.622 & 149.514 & -127.730 \\
1994 & 17.798 & 236.050 & 253.848 & -218.252 \\
1995 & 141.133 & 166.510 & 307.643 & -25.377 \\
1996 & 92.403 & 244.062 & 336.465 & -151.659 \\
1997 & 144.981 & 376.748 & 521.729 & -231.767 \\
1998 & 95.385 & 405.525 & 500.910 & -310.140 \\
1999 & 106.073 & 379.048 & 485.121 & -272.975 \\
2000 & 59.448 & 508.037 & 567.485 & -448.589 \\
2001 & 69.527 & 615.347 & 684.874 & -545.820 \\
2002 & 54.276 & 838.827 & 893.103 & -784.551 \\
2003 & 53.705 & 987.443 & $1,041.148$ & -933.738 \\
2004 & 51.221 & $1,260.205$ & $1,311.426$ & $-1,208.984$ \\
2005 & 97.574 & $1,557.797$ & $1,655.371$ & $-1,460.223$ \\
2006 & 118.330 & $1,783.911$ & $1,902.241$ & $-1,665.581$ \\
2007 & 167.056 & $2,106.139$ & $2,273.195$ & $-1,939.083$ \\
2008 & 129.309 & $2,214.691$ & $2,344.000$ & $-2,085.382$ \\
2009 & 100.952 & $1,983.241$ & $2,084.193$ & $-1,882.289$ \\
2010 & 148.851 & $2,697.924$ & $2,846.775$ & $-2,549.073$ \\
2011 & 319.714 & $3,088.837$ & $\mathbf{3 , 4 0 8 . 5 5 1}$ & $-2,769.123$ \\
\hline
\end{tabular}

Nota: En las exportaciones de 1990 a 1994 la atribución de país sigue el criterio de país comprador. A partir de 1995 el criterio utilizado es el de país destino.

Fuente: Secretaría de Economía con datos del Banco de México

La estrategia mexicana para vender en Tailandia y el sureste asiático, e incluso a China, debe contar con la posibilidad de producir en Tailandia, Myanmar, Laos o Camboya, por ejemplo, con el objetivo de ser competitiva y cubrir el mercado regional. En este "descubrimiento" de la región asiática, la academia y el gobierno mexicanos pueden tener un papel relevante y el sector privado también, sobre todo con el patrocinio a universidades para realizar estudios pertinentes. 


\section{Comentarios finales}

A lo largo de casi cuarenta años de relaciones diplomáticas entre México y Tailandia no han existido complicaciones o malentendidos entre ambos, y si bien la falta de instrumentos jurídicos bilaterales no ha impedido la colaboración recíproca en diversos ámbitos, es necesario alimentar el marco jurídico entre ambos países para dotar a la relación de bases sólidas y reglas que permitan una mejor interacción y cooperación en temas bilaterales y asuntos globales riesgosos que pueden afectar la relación o la esfera doméstica de cada nación.

Aspectos como el turismo, la cultura -gastronomía incluida-, el deporte y el idioma español, en el caso mexicano, son vehículos que deben aprovecharse para reforzar la relación de Asia y Latinoamérica y especialmente de México con el sureste asiático en general, y con Tailandia en particular.

El comercio bilateral, tal como se ha dicho antes, ha ido creciendo, casi sin interrupción, en los recientes veinte años, gracias a las leyes del mercado internacional y no necesariamente como resultado de políticas públicas, lo que permite vislumbrar amplias oportunidades si México o Tailandia lo consideran en sus estrategias nacionales, no limitadas a ellos mismos, sino de cara a sus regiones (sureste asiático y Latinoamérica), pero tampoco necesariamente como parte de mecanismos, foros o tratados regionales multilaterales, aunque de modo alguno se sugiere dejarlos fuera, y ahí está la TPP, por mencionar uno. No hay que desdeñar la amplia población y áreas de la ANSEA y de Norteamérica y Latinoamérica, con oportunidades para el comercio y la inversión a través de ambos países. La producción de manufacturas también puede trasladarse de región para ser más competitiva y aprovechar las cadenas de valor agregado.

Todo lo anterior requiere, sin embargo, de estimular el conocimiento mutuo en todos los niveles, aprovechando la riqueza cultural de la república mexicana y el reino tailandés, que sorpresivamente también pueden tener similitudes. En esta tarea es relevante el papel de todos los sectores en ambos países, comenzando por el gubernamental, con el apoyo de la iniciativa privada y con la elaboración de estudios de los centros de investigación universitarios en México y Tailandia que sirvan para la toma de decisiones en los diversos niveles del gobierno y la empresa.

Se trata de aprovechar la Cuenca del Pacífico como vía de comunicación y encuentro y no de muro que divide. Verbos como promover, cooperar, pactar, aliar, transportar, difundir y comerciar, son los que deben prevalecer entre 
Latinoamérica y Asia. La Nao de China ya lo demostró hace cinco siglos a través del océano Pacífico.

\section{Bibliografía}

ASEAN (2009), Your Gateway to an Economic Community, catalogue, ASEAN Secretariat, Jakarta, Indonesia, agosto.

Amparo Tello, Dagoberto (2001), "La política exterior de Tailandia y su participación en la ASEAN, el ARF y el APEC", México y la Cuenca del Pacífico, 4(12), pp. 22-26, Universidad de Guadalajara.

Economic and Social Survey of Asia and the Pacific 2012. Pursuing Shared Prosperity in an Era of Turbulence and High Commodity Prices (2012), United Nations Economic and Social Commission for Asia and the Pacific, Bangkok, mayo. Embajada Real de Tailandia en México (coord.) (2006), Lazos de amistad, 30 años Tailandia-México, Bangkok.

Falck, Melba E. (2001), "La economía de Tailandia", México y la Cuenca del Pacífico, 4(12), pp. 31-39, Universidad de Guadalajara.

- - (2010), "Presentación", México y la Cuenca del Pacífico, 13(39), pp. 7-12, Departamento de Estudios del Pacífico, Centro Universitario de Ciencias Sociales y Humanidades, Universidad de Guadalajara.

Foreign Office, Public Relations Department, (coord.) (2010), Thailand in Brief, Office of the Prime Minister, Bangkok.

González García, Juan (2001), "La recuperación económica poscrisis en Tailandia”, México y la Cuenca del Pacífico, 4(12), pp. 58-62, Universidad de Guadalajara.

Hearn, Adrian H. y José Luis León-Manríquez, Jose Luis (ed.) (2011), China Engages Latin America, Tracing the Trajectory, Boulder, Colorado, USA, Lynne Rienner Publishers.

Mahbubani, Kishore (2012), "The Lady should look to Asia, not Europe", The Straits Times and Financial Times, 1 June 2012.

México: Relación de tratados en vigor 1836-2010 (2011), $5^{\text {a }}$ ed., SRE. Mols, Manfred (2010), “¿Del siglo norteamericano al siglo asiático?”, México y la Cuenca del Pacífico, 13(39), pp.13-45, Universidad de Guadalajara.

Montaño, Jorge y Lozoya, Emilio (2012), "Propuestas para la próxima política exterior de México”, Foreign Affairs Latinoamérica, 12(2), México, ITAM. 
Pholphirul Piriya, Thomas (2007), "Labor-Market Issues under Trade Liberalization: Implications for Thai Workers”, Asia Pacific Development Journal, 14(1), Bangkok, UNESCAP.

Ramírez Meda, Kenia María (2009), "Evolución de las relaciones MéxicoTailandia: resultados, retos y propuestas”, México y la Cuenca del Pacífico, 12(34), pp. 87-103, Universidad de Guadalajara.

The Report, Thailand 2012 (2012), Oxford Business Group, agosto.

Robledo Padilla, Ramón (2001), "La cultura en las nuevas relaciones internacionales de Tailandia”, México y la Cuenca del Pacífico, 4(12), pp. 17-21, Universidad de Guadalajara.

Rodríguez Alegría, Agustina, "El comercio de Tailandia y su relación con México", México y la Cuenca del Pacífico, 4(12), pp. 40-45, Universidad de Guadalajara.

Sricharoen, Thitiwan; Buchenrieder, Gertrud y Thomas Dufhues (2008), "Universal Health-care Demands in Rural Northern Thailand: Gender and Ethnicity". Asia Pacific Development Journal, 15(1), Bangkok, UNESCAP.

Portales electrónicos

ANSEA, www.aseansec.org

APEC, www.apec.org

Banco Central do Brasil, www.bcb.gov.br

Banco de Tailandia, www.bot.or.th

Dirección de Promoción de Exportaciones, Chile, rc.prochile.gov.cl FOCALAE, www.fealac.org

Instituto Brasileiro de Geografia e Estatistica, www.ibge.gov.br/home

International Trade Centre (ITC), Market Analysis Tools, www.intracen.org, http://legacy.intracen.org/marketanalysis/Default.aspx

Ministerio de Desarrollo, Industria y Comercio Exterior. Brasil, Secretaría de Comercio Exterior, www.desenvolvimento.gov.br/sitio/interna/index. php?area $=5$

National Statistical Office of Thailand, www.nso.go.th

ProMéxico/Inversión y Comercio, México, www.promexico.gob.mx

Superintendencia Nacional de Aduanas y de Administración Tributaria, Perú, www.sunat.gob.pe 